\title{
AÇÃO RESIDUAL DE INSETICIDAS PARA LARVAS E ADULTOS DO PREDADOR CYCLONEDA SANGUINEA LINNAEUS, 1763 (COLEOPTERA: COCCINELLIDAE)
}

\author{
M.I.S. Leite, G.A. Carvalho, J.B. Maia, L. Makiyama, M. Vilela
}

Universidade Federal de Lavras, Departamento de Entomologia, CP 3037, CEP 37200-000, Lavras, MG, Brasil. E-mail:maryisabbella@yahoo.com.br

\section{RESUMO}

A ação residual dos inseticidas imidacloprido/Beta-ciflutrina, clotianidina e clorfenapir foi avaliada para larvas de terceiro ínstar e adultos do predador Cycloneda sanguinea (Linnaeus). Sementes de algodão da cultivar BRS IPE foram semeadas em vasos de PVC e as plantas foram mantidas em casa de vegetação. Ao atingirem 25 dias de idade, as plantas foram pulverizadas com os produtos nas menores dosagens recomendadas pelos fabricantes, utilizando-se pulverizador manual. As concentrações foram em g i.a. $L^{-1}$ de água: imidacloprido/Beta-ciflutrina (100/12,5 SC - 0,25/0,03), clotianidina (500 PM - 0,33) e clorfenapir (240 SC - 0,80). Água destilada foi utilizada como testemunha. Folhas previamente marcadas em cada planta, de cada tratamento, foram retiradas e levadas ao laboratório e colocadas em placas de Petri contendo solução de ágar bacteriológico. Ovos de Anagasta kuehniella (Zeller) foram colocados sobre as folhas de algodoeiro e, em seguida, liberou-se um espécime por placa. As liberações ocorreram após 1, 12, 23 e 35 dias da pulverização dos compostos. Cada placa de Petri foi imediatamente vedada com filme de plástico PVC. O delineamento foi inteiramente casualizado com quatro tratamentos e doze repetições sendo que, para os testes com larvas, cada parcela foi formada por três espécimes e, para aqueles com adultos, cada repetição correspondeu a um casal. As avaliações de mortalidade foram feitas após 12, 24 e 48 horas das liberações. Os produtos foram classificados de acordo com o proposto pela Organização Internacional para Controle Biológico (IOBC). Todos os produtos foram enquadrados na classe $4=$ persistentes, visto que mesmo a partir do trigésimo dia após sua aplicação causaram mais de 30,0\% de mortalidade dos predadores.

PALAVRAS-CHAVE: Algodoeiro, inimigo natural, produtos fitossanitários, seletividade.

\section{ABSTRACT}

RESIDUAL ACTION OF INSECTICIDES TO LARVAE AND ADULTS OF THE PREDATOR CYCLONEDA SANGUINEA LINNAEUS, 1763 (COLEOPTERA: COCCINELLIDAE). The residual action of the insecticides imidacloprid/Beta-cyfluthrin, clothianidin and chlorfenapyr was evaluated in regard to third-instar larvae and adults of the predator Cycloneda sanguinea (Linnaeus). Cotton seeds of the cultivar BRS IPE were sowed in PVC pots and the plants were maintained in the greenhouse. Upon reaching 25 days of age, the plants were sprayed with the lowest dosages of the products recommended by the manufacturers, using a manual sprayer. The insecticides evaluated in $\mathrm{g}$ a.i. $\mathrm{L}^{-1}$ of water were imidacloprid/Beta-cyfluthrin (Imidacloprido/Beta-ciflutrina 100/12.5 CS - 0.25/0.03), clothianidin (Clotianidina $500 \mathrm{WP}-0.33$ ) and chlorfenapyr (Clorfenapir 240 CS0.80). Distilled water was used as a control. Previously marked leaves, from each treatment, were removed from the plants and taken to the laboratory where they were placed in Petri dishes containing bacteriologic agar solution. Eggs of Anagasta kuehniella (Zeller) were placed on cotton leaves following the release of a Trichogramma specimen per dish after 1, 12, 23 and 35 days from pesticides application. Each Petri dish was immediately closed with plastic PVC film. A completely randomized experimental design was used, with 4 treatments and 12 replicates, each one formed by 3 third-instar larvae or 1 couple of adults. The number of dead larvae and adults in each treatment was examined 12, 24 and 48 hours after exposure to the chemicals. The products were classified according to categories proposed by the International Organization for Biological Control (IOBC). All the compounds tested were evaluated as class 4 = persistent, causing mortality above $30 \%$ up to 31 days after application on cotton leaves.

KEY WORDS: Cotton, natural enemy, pesticides, selectivity. 


\section{INTRODUÇÃO}

A agricultura mundial tem passado por várias mudanças tecnológicas, econômicas e sociais, com o intuito de aumentar a produtividade das culturas para sustentar uma população que, até 2012, atingirá aproximadamentesetebilhões depessoas (ORGANIZAÇÃODAS NAÇÕES UNIDAS, 2005). Nesse cenário, estãoinseridosos insetos e doenças que também sofrem alterações e acompanham essas mudanças, disseminando-se por regiões com as mais variadas condições climáticas e representando perdas cada vez maiores nas culturas.

Nesse contexto a cultura algodoeira merece destaque devido à sua grande importância econômica e social, visto ser a fibra vegetal mais utilizada pelo homem e, à sua grande vulnerabilidade ao ataque de pragas, recebendo por esse motivo diversas aplicações de pesticidas. Como consequência desse uso intensivo, tem-se o desenvolvimento de resistência, o surto de pragas secundárias, a ressurgência de pragas primárias, a intoxicação do homem e animais, a contaminação do ambiente e o aumento do custo de produção (SANTOS, 1999; ARAUjo et al., 2000).

Uma alternativa econômica e ambientalmente viável para o controle das pragas do algodoeiro é a incorporaçãoeintegraçãodetáticas quecompõemoManejo Integrado de Pragas (MIP). Entre elas pode-se citar a utilização de agentes de controle biológico e a sua conservação no sistema agrícola, visando o equilíbrio dinâmico das populações de insetos-praga e o uso de produtos fitossanitários seletivos, ou seja, que atuem contra as espécies-alvo que tenham o menor impacto possível sobre as populações de espécies benéficas (Degrande; Gomez, 1990; Y АмAMOto et al., 1992).

Entre o complexo de pragas do algodoeiro, o pulgão Aphis gossypii Glover, 1877 (Hemiptera: Aphididae) tem se destacado pelo aumento da resistência aos inseticidas e escape à predação e ao parasitismo, podendo provocar reduções deaté $40,0 \%$ na produção (PASSOS, 1977; WeATHERSBEe III; HARDEE, 1994). A densidade populacional dessa e de outras pragas pode ser reduzida por vários agentes de controlebiológico que ocorrem naturalmentenessa cultura, prevalecendo os predadores pertencentes à família Coccinellidae (EvANGELISTA-JúNIOR et al., 2006).

Em estudo realizado por RIBEIRO (2007), visando realizar levantamento das espécies de predadores predominantes na cultura algodoeira, constatou-se que na safra 2005/2006, Cycloneda sanguinea Linnaeus, 1763 (Coleoptera: Coccinellidae) representou $55,0 \%$ dos inimigos naturais encontrados, verificando-se a existência, abundância e necessidade de se preservar esse inimigo natural para estabelecer o equilíbrio dinâmico de pragas nesse agroecossistema.

Trabalhos que visem conhecer a ação residual de inseticidas a insetos estão se tornando frequentes nas pesquisas atuais; entretanto, não estão registrados em literatura recente trabalhos que avaliem o efeito residual de inseticidas ao predador C. sanguinea. Tendo em vista que a toxicidade dos compostos depende de vários fatores e não exclusivamente da espécie de inseto estudada, resultados encontrados para espécies diferentes podem corroborar os resultados encontrados no presente trabalho.

Sendo assim, este trabalho teve por objetivo avaliar o efeito residual de alguns inseticidas sintéticos, em suas menores dosagens recomendadas para o controle de pragas do algodoeiro, sobre larvas de terceiro ínstar e adultos do predador C. sanguinea.

\section{MATERIALEMÉTODOS}

Para criação do predador C. sanguinea em laboratório, espécimes foram coletados em plantas de citros juntoaopomardoCampusdaUniversidadeFederalde Lavras (UFLA) e mantidos em gaiolas de PVC com 10 cm de diâmetrox $10 \mathrm{~cm}$ dealtura, vedadasnas extremidades superior einferior com filmeplásticoPVC.Como substrato para oviposição, os recipientes foram revestidos internamente com papel-filtro. Pulgões foram coletados em plantas dealgodoeiro cultivadas em casa devegetaçãoe ofertadosad libitum como alimento, três vezes por semana e, quandonecessário, a alimentação foi suplementada com ovos de Anagasta kuehniella (Zeller, 1879) (Lepidoptera:Pyralidae). A metodologia de criação foi adaptada de Cosme et al. (2007) e esta foi mantida sob condições controladas $\left(24 \pm 2^{\circ} \mathrm{C}\right.$, UR de 60 $\pm 10 \%$ e fotofase de $12 \mathrm{~h}$ ).

Para execução dos experimentos, três sementes de algodão da cultivar BRSIPÊ foram semeadas por vaso de PVC, com capacidade para $3 \mathrm{~L}$ contendo terra e esterco bovino, na proporção $60,0 \%$ e $40,0 \%$, respectivamente. Os vasos foram mantidos em condição de casa de vegetação durante todo o período de realização dos experimentos. Uma semana após a semeadura, foi feito o desbaste, mantendo-se apenas a planta mais vigorosa. Ao atingirem 25 dias de idade, as plantas foram tratadas por meio da pulverização das caldas químicas atéo ponto de escorrimento, utilizando-se pulverizador manual com volume de $0,5 \mathrm{~L}$.

Os inseticidas e as concentrações avaliadas foram em g i.a. $\mathrm{L}^{-1}$ de água: imidacloprido/Beta-ciflutrina (Connect 100/12,5SC-0,25/0,03), clotianidina (Focus 500 PM-0,33) eclorfenapir(Pirate240SC-0,80). Água destilada foi utilizada como testemunha.

Trinta minutos após a pulverização, algumas folhas que receberam os produtos foram marcadas com corretivo branco não tóxico e, em seguida, as plantas foram isoladas em gaiolas plásticas transparentes para evitarmistura desubstâncias. Asfolhas marcadas foram utilizadas após 1, 12, 23 e 35 dias da pulveriza- 
ção dos inseticidas, deacordo com recomendações da IOBC (Hassan; Degrande, 1996; HASSAN, 1997). Nas datas estabelecidas para serem utilizadas, as folhas marcadas em cada tratamento foram retiradas das plantas e levadas ao laboratório para a realização dos testes. Em seguida, foram colocadas no interior de cada placa de Petri (5 cm de diâmetro), contendo aproximadamente $10 \mathrm{~mL}$ de solução de ágar bacteriológico na proporção de 24 g de ágar para cada $1 \mathrm{~L}$ de água. Trinta minutos após a solidificação do ágar, ovos de A. kuehniella foram colocados sobre as folhas para a alimentação de C. sanguinea. Posteriormente, liberou-se uma larva de terceiro ínstar ou um adulto em cada placa. As placas foram vedadas com filme plástico de PVC e mantidas em bandejas de plástico no interior de câmaras climatizadas à $25 \pm 1^{\circ} \mathrm{C}$, umidade relativa de $70 \pm 10 \%$ e fotofase de 12 horas.

Odelineamento experimental utilizad o foi o inteiramente casualizado com 12 repetições para cada tratamento, sendo que, para os ensaios com larvas, cada parcela foi composta por três espécimes de terceiro ínstar e, para aqueles com adultos, cada uma foi constituída por um casal. As avaliações de mortalidade foram realizadas após 12, 24 e 48 horas da liberação dos insetos sobre as folhas, pela contagem do número de espécimes mortos.

Os dados referentes à mortalidade dos predadores foram transformados para $\sqrt{X+1}$ esubmetidos à análise de variância, sendo as médias dos tratamentos comparadas pelo teste de Tukey $(\mathrm{P} \leq 0,05)$. Realizouse análise de regressão polinomial para avaliar a ação dos produtos ao longo do tempo. Todas as análises foram feitas utilizando-se o programa estatístico SISVAR (FERREIRA, 2000; FERREIRA, 2005).

A reduçãono número delarvas eadultos do predador causada pela ação dos inseticidas foi comparada com o tratamento testemunha, sendo utilizada como parâmetro de classificação da toxicidade dos produtos. Assim, os produtos foram classificados de acordo com as categorias apresentadas por HASSAN; DEGRANDE (1996) e HASSAN (1997), sendo: classe 1 = pouco persistente ( $<5$ dias), classe 2 = levemente persistente $(5-15$ dias), classe 3 = moderadamente persistente (16-30 dias) e classe $4=$ persistente ( $>30$ dias).

\section{RESULTADOSEDISCUSSÃO}

Larvas de terceiro ínstar e adultos de C. sanguinea, quando expostos aos inseticidas em folhas de algodoeiro, foram afetados em todas as liberações. Verificouse que, $12 \mathrm{~h}$ após a primeira liberação (24h após a pulverização das plantas) de larvas de terceiro ínstar sobrefolhas contendoimidacloprido/Beta-ciflutrinae clotianidina, ocorreram $91,67 \%$ e $80,55 \%$ demortalidade, respectivamente, sendo que nos tratamentos con- trole e à base de clorfenapir nenhuma mortalidade foi verificada. Foi observado que, $24 \mathrm{~h}$ após a primeira liberação das larvas dajoaninha, imidacloprido/Betaciflutrina causou 100,00\% demortalidade; clotianidina $80,55 \%$ e clorfenapir $52,77 \%$, enquanto $0,00 \%$ de mortalidade foi observado na testemunha. Às $48 \mathrm{~h}$ da primeira liberação, imidacloprido/Beta-ciflutina, clotianidina e clorfenapir apresentaram médias de $100,00 \%, 97,22 \%$ e 100,00\%, respectivamente, sendo que todos os insetos mantiveram-se vivos na testemunha. Médias menores foram observadas para os tratamentos clotianidina e clorfenapir $48 \mathrm{~h}$ após a liberação dos espécimes, quandoa segunda liberação foi feita, 12 dias após a pulverização, sendo de 80,55\% e 86,11\%, respectivamente. Nesta liberação, a maior média de mortalidade foi alcançada para imidacloprido/Betaciflutrina $(100,0 \%)$,48h após a sua pulverização, sendo observada média de $11,1 \%$ de morte no tratamento testemunha (Tabela 1 e Fig. 1A).

Nas terceira e quarta liberações realizadas após 23 e 35 dias da pulverização dos produtos, 5,56\% de mortalidade foi observada para a testemunha até $48 \mathrm{~h}$ após o início dos experimentos. Ao mesmo tempo, imidacloprido/Beta-ciflutrina afetou os espécimes causando mortede $97,22 \%$ e 100,00\%,respectivamente. Clotianidina causou $100,00 \%$ de mortalidade na avaliação realizada 24 h após a terceira liberação e $91,67 \%$ 48h após a quarta liberação; enquanto clorfenapir apresentou médias de 51,39\% e 47,22\%, respectivamente (Tabela 1 e Fig. 1A).

Quando adultos do predador C. sanguinea foram colocados em contato com folhas de algodoeiro, um dia após a aplicação dos produtos sobre as plantas, altas taxas de mortalidade foram observadas para os três inseticidas testados. Foi constatado 100,00\% de mortalidadenos tratamentosàbasedeimidacloprido/ Beta-ciflutrina e clotianidina após $24 \mathrm{~h}$ da liberação dos predadores, sendo que o mesmo valor foi observado para o clorfenapir 48h após a exposição dos espécimes ao produto. Na segunda liberação, realizada 12 dias após a pulverização dos produtos, imidacloprido/Beta-ciflutrina e clotianidina causaram mortalidade de 100,00\% dos predadores após $24 \mathrm{~h}$ e $48 \mathrm{~h}$, respectivamente. A maior média foi verificada para o tratamento com clorfenapir com $91,67 \%$ de mortalidade após $48 \mathrm{~h}$ de contato dos insetos com as folhas (Tabela 2 e Fig. 1B). Vinte e três dias após a pulverização das plantas com os produtos, a sobrevivência dos insetos foi afetada em 87,50\% e $91,67 \%$, respectivamente, para clotianidina e clorfenapir, na avaliação realizada $48 \mathrm{~h}$ após. Imidacloprido/Beta-ciflutrina causou mortalidade de 100,00\% dos espécimes, enquanto quena testemunha nenhuma morte foi observada até $48 \mathrm{~h}$ após a exposição dos insetos. Na última liberação, 35 dias após a contaminação das folhas, os menores valores 
de mortalidade foram observados para os três inseticidas testados, sendo que imidacloprido/Betaciflutrina, clotianidina e clorfenapir causaram, respectivamente, $91,67 \% ; 70,83 \%$ e $79,17 \%$ de mortalidade após 48h. Na testemunha a sobrevivência não foi afetada (Tabela 2 e Fig. 1B).

Oefeito residual de produtos fitossanitários pode ser afetado por diversos fatores bióticos e abióticos entre eles pode-se citar a degradação do composto pela atividade metabólica da planta, as condições climáticas, o mecanismo de ação do produto, o tipo de solo, a metodologia de pulverização dos compostose a própria espécie ou variedade da planta (GALLOetal., 2002). Sendo assim, é de se esperar que, ao longo do tempo, as moléculas tóxicas tenham seu potencial de ação diminuído por algum dos fatores acima citados e com isso menores valores de mortalidade sejam observados. Na presente pesquisa, índices menores de mortalidade foram observados para a liberação realizada 35 dias após a contaminação em relação aquela feita um dia após a contaminação das plantas, quando larvas e adultos de C. sanguinea foram expostos aos resíduos dos compostos. Possivelmente, as moléculas inseticidas sofreram degradação ao longo do tempo de condução dos experimentos e, para os produtos cuja diminuição não foi significativa, podese inferir que a taxa de degradação não foi suficiente para interferir na letalidade do composto. Entretanto, não é possível afirmar a causa dessa degradação uma vez que em casa de vegetação, apesar de estarem mais protegidas do que em campo, as plantas contendo os produtos não estão isentas de variações de temperatura, umidade relativa e incidência deluz solar, entre outros.

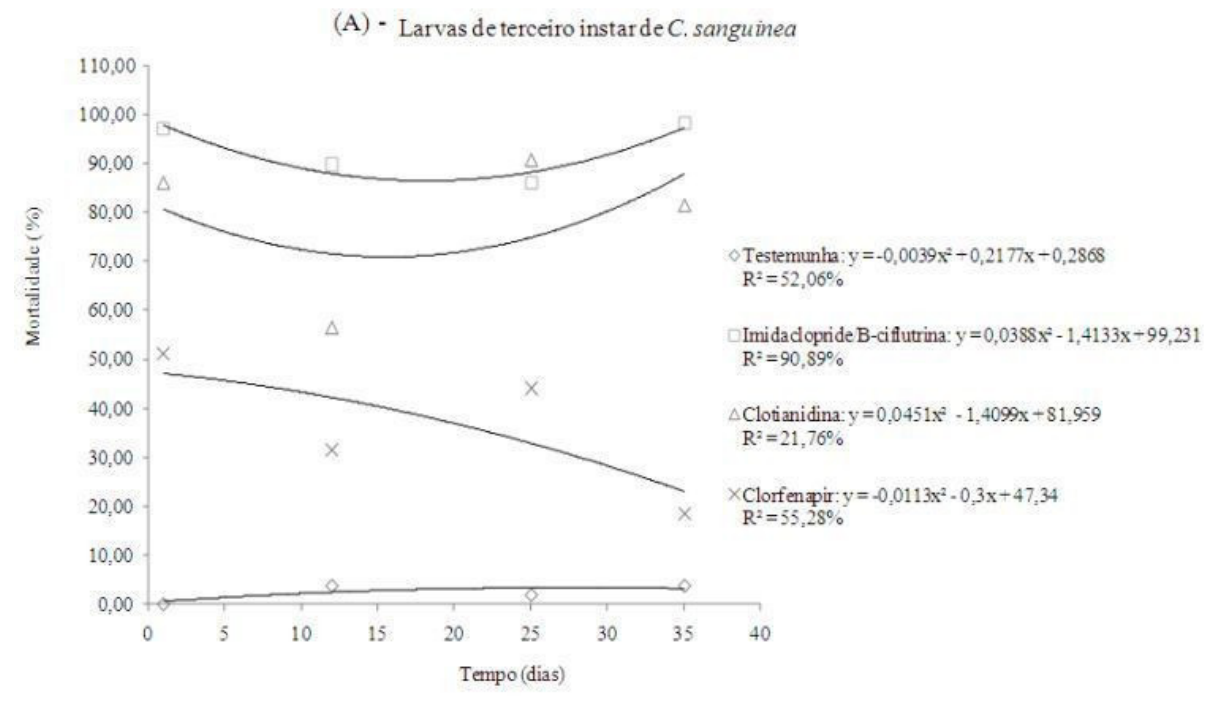

(B) - Adultos de C. sanguinea

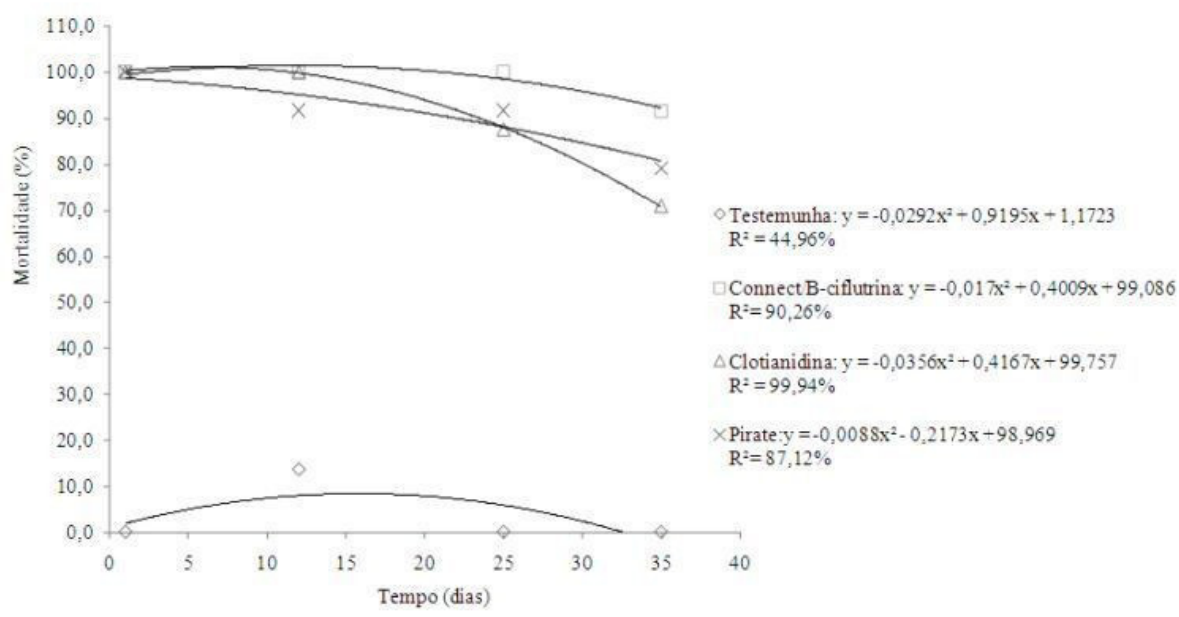

Fig. 1 - Curvas de mortalidade de larvas de terceiro instar (A) e adultos (B) de Cycloneda sanguinea tratados com os inseticidas para o controle de pragas da cultura algodoeira. 
Tabela 1 - Mortalidade (\%) de larvas de terceiro instar de Cycloneda sanguinea (média ${ }^{1} \pm \mathrm{EP}$ ) provocada pelo efeito residual de inseticidas para o controle de pragas da cultura algodoeira.

\begin{tabular}{|c|c|c|c|c|c|c|}
\hline \multirow[t]{3}{*}{ Tratamento [g i.a.L- $\left.{ }^{-1}\right]$} & \multicolumn{6}{|c|}{ Avaliação } \\
\hline & \multicolumn{3}{|c|}{$1^{a}$ liberação (1 dia após a liberação) } & \multicolumn{3}{|c|}{ 2ª liberação (12 dias após a liberação) } \\
\hline & $12 \mathrm{~h}$ & $24 \mathrm{~h}$ & $48 \mathrm{~h}$ & $12 \mathrm{~h}$ & $24 \mathrm{~h}$ & $48 \mathrm{~h}$ \\
\hline $\begin{array}{l}\text { Água destilada } \\
\text { Imidacloprido/ } \\
\text { Beta-ciflutrina } \\
(0,25 / 0,03)\end{array}$ & $\begin{array}{r}0,00 \pm 0,00 \mathrm{a} \\
91,67 \pm 1,26 \mathrm{~b}\end{array}$ & $\begin{array}{r}0,00 \pm 0,00 \mathrm{a} \\
100,00 \pm 0,00 \mathrm{c}\end{array}$ & $\begin{array}{r}0,00 \pm 0,00 \mathrm{a} \\
100,00 \pm 0,00 \mathrm{~b}\end{array}$ & $\begin{array}{r}0,00 \pm 0,00 \mathrm{a} \\
72,22 \pm 1,60 \mathrm{c}\end{array}$ & $\begin{array}{r}0,00 \pm 0,00 a \\
97,22 \pm 0,80 c\end{array}$ & $\begin{array}{r}11,11 \pm 2,47 a \\
100,00 \pm 0,00 b\end{array}$ \\
\hline Clotianidina $(0,33)$ & $80,55 \pm 2,20 b$ & $80,55 \pm 2,20 \mathrm{c}$ & $97,22 \pm 0,80 \mathrm{~b}$ & $36,11 \pm 2,20 b$ & $52,77 \pm 2,76 b$ & $80,55 \pm 2,20 b$ \\
\hline Clorfenapir $(0,80)$ & $0,00 \pm 0,00 \mathrm{a}$ & $52,77 \pm 2,20 \mathrm{~b}$ & $100,00 \pm 0,00 \mathrm{~b}$ & $0,00 \pm 0,00 \mathrm{a}$ & $8,33 \pm 1,26 a$ & $86,11 \pm 1,43 \mathrm{~b}$ \\
\hline $\mathrm{CV}(\%)$ & 4,52 & 6,3 & 1,36 & 5,74 & 7,13 & 6,56 \\
\hline \multirow[t]{2}{*}{ Tratamento [g i.a.L-1] } & \multicolumn{3}{|c|}{$3^{\text {a }}$ liberação (23 dias após a liberação) } & \multicolumn{3}{|c|}{$4^{a}$ liberação (35 dias após a liberação) } \\
\hline & $12 \mathrm{~h}$ & $24 \mathrm{~h}$ & $48 \mathrm{~h}$ & $12 \mathrm{~h}$ & $24 \mathrm{~h}$ & $48 \mathrm{~h}$ \\
\hline $\begin{array}{l}\text { Água destilada } \\
\text { Imidacloprido/ } \\
\text { Beta-ciflutrina } \\
(0,25 / 0,03)\end{array}$ & $\begin{array}{r}0,00 \pm 0,00 \mathrm{a} \\
63,88 \pm 2,20 \mathrm{~b}\end{array}$ & $\begin{array}{r}0,00 \pm 0,00 \mathrm{a} \\
97,22 \pm 0,80 \mathrm{c}\end{array}$ & $\begin{array}{r}5,56 \pm 1,60 \mathrm{a} \\
97,22 \pm 0,80 \mathrm{c}\end{array}$ & $\begin{array}{r}0,00 \pm 0,00 \mathrm{a} \\
97,22 \pm 0,80 \mathrm{c}\end{array}$ & $\begin{array}{r}5,56 \pm 1,08 a \\
97,22 \pm 0,80 c\end{array}$ & $\begin{array}{r}5,56 \pm 1,08 a \\
100,00 \pm 0,00 c\end{array}$ \\
\hline Clotianidina $(0,33)$ & $72,22 \pm 2,32 b$ & $100,00 \pm 0,00 c$ & $100,00 \pm 0,00 c$ & $77,78 \pm 2,16 b$ & $75,00 \pm 2,41 b$ & $91,67 \pm 1,26 c$ \\
\hline Clorfenapir $(0,80)$ & $2,78 \pm 0,80 \mathrm{a}$ & $51,39 \pm 2,74 b$ & $77,78 \pm 2,16 b$ & $0,00 \pm 0,00 \mathrm{a}$ & $8,33 \pm 1,26 a$ & $47,22 \pm 2,50 \mathrm{~b}$ \\
\hline CV (\%) & 7,55 & 5,67 & 5,08 & 4,22 & 5,89 & 6,13 \\
\hline
\end{tabular}

${ }^{1}$ Médias seguidas de mesma letra na coluna não diferem estatisticamente pelo teste de Tukey $\mathrm{P}(\leq 0,05)$.

Tabela 2 - Mortalidade (\%) de adultos de Cycloneda sanguinea (média ${ }^{ \pm} \pm$EP) provocada pelo efeito residual de inseticidas para o controle de pragas da cultura algodoeira.

\begin{tabular}{|c|c|c|c|c|c|c|}
\hline \multirow[t]{3}{*}{ Tratamento [g i.a.L-1] } & \multicolumn{6}{|c|}{ Avaliação } \\
\hline & \multicolumn{3}{|c|}{$1^{a}$ liberação (1 dia após a liberação) } & \multicolumn{3}{|c|}{ 2ª liberação (12 dias após a liberação) } \\
\hline & $12 \mathrm{~h}$ & $24 \mathrm{~h}$ & $48 \mathrm{~h}$ & $12 \mathrm{~h}$ & $24 \mathrm{~h}$ & $48 \mathrm{~h}$ \\
\hline Água destilada & $0,00 \pm 0,00 \mathrm{a}$ & $0,00 \pm 0,00 \mathrm{a}$ & $0,00 \pm 0,00 \mathrm{a}$ & $0,00 \pm 0,00 \mathrm{a}$ & $4,17 \pm 1,20 \mathrm{a}$ & $12,50 \pm 1,89 a$ \\
\hline $\begin{array}{l}\text { Imidacloprido/ } \\
\text { Beta-ciflutrina } \\
(0,25 / 0,03)\end{array}$ & $83,33 \pm 2,05 c$ & $100,00 \pm 0,00 c$ & $100,00 \pm 0,00 b$ & $95,83 \pm 1,20 c$ & $100,00 \pm 0,00 c$ & $100,00 \pm 0,00 b$ \\
\hline Clotianidina $(0,33)$ & $50,00 \pm 3,55 b$ & $100,00 \pm 0,00 c$ & $100,00 \pm 0,00 b$ & $66,67 \pm 2,71 b$ & $79,17 \pm 2,15 c$ & $100,00 \pm 0,00 b$ \\
\hline Clorfenapir $(0,80)$ & $0,00 \pm 0,00 \mathrm{a}$ & $70,83 \pm 3,30 \mathrm{~b}$ & $100,00 \pm 0,00 \mathrm{~b}$ & $16,67 \pm 2,71 \mathrm{a}$ & $41,67 \pm 3,48 b$ & $91,67 \pm 2,40 b$ \\
\hline CV (\%) & 51,33 & 23,17 & - & 38,68 & 35,72 & 23,18 \\
\hline \multirow[t]{2}{*}{ Tratamento [g i.a.L-1] } & \multicolumn{3}{|c|}{$3^{\text {a }}$ liberação (23 dias após a liberação) } & \multicolumn{3}{|c|}{$4^{\mathrm{a}}$ liberação (35 dias após a liberação) } \\
\hline & $12 \mathrm{~h}$ & $24 \mathrm{~h}$ & $48 \mathrm{~h}$ & $12 \mathrm{~h}$ & $24 \mathrm{~h}$ & $48 \mathrm{~h}$ \\
\hline Água destilada & $0,00 \pm 0,00 \mathrm{a}$ & $0,00 \pm 0,00 \mathrm{a}$ & $0,00 \pm 0,00 a$ & $0,00 \pm 0,00 a$ & $0,00 \pm 0,00 \mathrm{a}$ & $0,00 \pm 0,00 a$ \\
\hline $\begin{array}{l}\text { Imidacloprido/ } \\
\text { Beta-ciflutrina } \\
(0,25 / 0,03)\end{array}$ & $83,33 \pm 2,05 b$ & $95,83 \pm 1,20 c$ & $100,00 \pm 0,00 b$ & $0,00 \pm 0,00 \mathrm{a}$ & $83,33 \pm 2,05 c$ & $91,67 \pm 1,62 b$ \\
\hline Clotianidina $(0,33)$ & $62,50 \pm 2,59 b$ & $75,00 \pm 2,18 b c$ & $87,50 \pm 1,88 b$ & $0,00 \pm 0,00 \mathrm{a}$ & $41,67 \pm 2,99 b$ & $70,83 \pm 2,15 b$ \\
\hline Clorfenapir $(0,80)$ & $0,00 \pm 0,00 \mathrm{a}$ & $50,00 \pm 3,08 b$ & $91,67 \pm 1,62 b$ & $0,00 \pm 0,00 \mathrm{a}$ & $41,67 \pm 3,44 b$ & $79,17 \pm 2,15 b$ \\
\hline $\mathrm{CV}(\%)$ & 6,75 & 7,82 & 4,56 & - & 11,03 & 6,21 \\
\hline
\end{tabular}

${ }^{1}$ Médias seguidas de mesma letra na coluna não diferem estatisticamente pelo teste de Tukey $\mathrm{P}(\leq 0,05)$. 
Em função da alta mortalidade verificada ao longo das avaliações, todos os produtos testados foram considerados persistentes e enquadrados na classe 4 proposta pela IOBC, já que até os 35 dias após as pulverizações causaram redução de sobrevivência abaixo de 30,0\% (Fig. 1A e 1B).

Costa et al. (2003) avaliaram a ação residual de produtos fitossanitários a larvas de Chrysoperlaexterna (Hagen, 1861) (Neuroptera: Chrysopidae) quando pulverizados sobre plantas de algodoeiro e verificaram que os inseticidas fenpropatrina e clorpirifós causaram menos de $30,0 \%$ de sobrevivência aos 25 dias após a aplicação dos produtos, sendo classificados como moderadamente persistentes (Classe 3). Esses compostos pertencem, respectivamente, aogrupoquímico dos piretroides assim como Beta-ciflutrina, e ao grupo dos organofosforados assim como clorpirifós.

As altas mortalidades observadas, inclusive após um período de mais de 30 dias após a pulverização dos compostos, pode ser explicada pelo mecanismo de ação dos produtos. Imidacloprido/Beta-ciflutrina é um composto que conjuga dois princípios ativos pertencentes a grupos químicos diferentes, o primeiro ao grupo dos neonicotinoides, assim como clotianidina, eosegundoaogrupodos piretroides. Ostrês princípios ativos citados são neurotóxicos e levam os insetos à morte por causarem hiperexcitabilidade do sistema nervoso, porém, os neonicotinoides são agonistas da acetilcolina, ou seja, seligam aos receptoresnicotínicos presentes nos neurônios, e os piretróides atuam nos canais de sódio retardando seu fechamento e com isso permitindo um alto influxo de sódio que irá desencadear sucessivos impulsos nervosos (RIGITANO; CARVALHO, 2001; GALLO et al., 2002; CORREIA et al., 2005).

Oterceirocomposto, quetambém causou altas mortalidades, não age como os demais, mas é responsável por inibir uma molécula essencial para a sobrevivência dos seres vivos, a ATP. Essa molécula é armazenada pelos seres vivos e é uma das fontes de energia para a realização das reações químicas (GALLO et al., 2002).

\section{CONCLUSÕES}

Os inseticidas imidacloprido/Beta-ciflutrina, clotianidina e clorfenapir nas menores dosagens recomendadas pelos fabricantes para o controle de pragas da cultura algodoeira são persistentes, causando mortalidades acima de $30,00 \%$ até os 35 dias após a pulverização das plantas.

\section{AGRADECIMENTOS}

À CAPES pela concessão de bolsa de estudo e à FAPEMIG pelo apoio financeiro.

\section{REFERÊNCIAS}

ARAUJO, L.H.A.; BLEICHER, E.S.L.; QUEIROZ, S.; QUEIROZ, J.C. Manejo da mosca-branca Bemisia argentifolii Bellows \& Perring no algodoeiro. Campina Grande: EMBRAPA-CNPA, 2000. 34p. (Circular Técnica, 40).

CORREIA, T.R.; SCOTT, F.B.; FERNANDES, J.I.; MELO, R.M.P.S.; VEROCAI, G.G.; SOUZA, C.P. Eficácia do regulador de crescimento de insetos piriproxifen associado ao piretróide d-fenotrina (Mypet ${ }^{\circledR}$ aerosol) no controle ambiental de Ctenocephalides felis felis (Bouché, 1835) (Siphonaptera: Pulicidae). A Hora Veterinária, v.146, p.27-31, 2005.

COSME, L.V.; CARVALHO, G.A.; MOURA, A.P. Efeitos de inseticidas botânico e sintéticos sobre ovos e larvas de Cycloneda sanguinea (Linnaeus) (Coleoptera: Coccinellidae) em condições de laboratório. Arquivos do Instituto Biológico, São Paulo, v.74, p.251-258, 2007.

COSTA, D.B.; SOUZA, B.; CARVALHO, G.A.; CARVALHO, C.F. Residual action of insecticides to larvae of Chrysoperla externa (Hagen, 1861) (Neuroptera: Chrysopidae) under greenhouse conditions. Ciência e Agrotecnologia, v.27, p. 835-839, 2003.

DEGRANDE, P.E.; GOMEZ, D.R.S. Seletividade de produtos químicos no controle de pragas. Agrotécnica Ciba-Geigy, v.7, n.1, p.8-13, 1990.

EVANGELISTA JÚNIOR, W.S.; ZANUNCIO JÚNIOR, J.S.; ZANUNCIO, J.C. Controle biológico de artrópodes pragas do algodoeiro com predadores e parasitóides. Revista Brasileira de Oleaginosas e Fibrosas, v.10, n.3, p.1147-1165, 2006.

FERREIRA, D.F. SISVAR - programa estatístico. Versão 5.0 (Build 66). Lavras: Universidade Federal de Lavras. 2000.

FERREIRA, D.F. Estatística básica. Lavras: Editora UFLA, 2005. 664p.

GALLO, D.; NAKANO, O.; SILVEIRA NETO, S.; CARVALHO, R.P.L.; BATISTA, G.C.; BERTI FILHO, E.; PARRA, J.R.P.; ZUCCHI, R.A.; ALVES, S.B.; VENDRAMIM, J.D.; MARCHINI, L.C.; LOPES, J. R. S.; OMOTO, C. Entomologia agrícola. Piracicaba: FEALQ, 2002. 920p.

HASSAN, S.A. Métodos padronizados para testes de seletividade com ênfase em Trichogramma. In: PARRA, J.R.P.; ZUCCHI, R. (Ed.). Trichogramma e o controle biológico aplicado. Piracicaba: FEALQ, 1997. Cap.8, p.207-233.

HASSAN, S.A.; DEGRANDE, P.E. Methods to test the side effects of pesticides on Trichogramma. Apud PARRA, J.R.P.; ZUCCHI, R. (Ed.) Curso de controle biológico com Trichogramma. Piracicaba: FEALQ, 1996. p.63-74. 
ORGANIZAÇÃO DAS NAÇÕES UNIDAS. População mundial. 2005. Disponível em: <http://www.un.org/ apps/news/Story.asp?NewsID $=13379 \& \mathrm{Cr}=$ populations\& $\mathrm{Cr}=1$ development $>$. Acesso em: $13 \mathrm{dez}$. 2005.

PASSOS, S.M.G. Algodão. Campinas: Instituto Campineiro de Ensino Agrícola, 1977. 424p.

RIBEIRO, J.F. Seletividade de inseticidas aos artrópodespredadores de pragas do algodoeiro em condições de campo. 2007. 36p. Dissertação (Mestrado em Agronomia Produção Vegetal) - Universidade Federal da Grande Dourados, Dourados, MS, 2007.

RIGITANO, R.L.O.; CARVALHO, G.A. Toxicologia e seletividade de inseticidas. Lavras: Ufla/Faepe. 2001. 72p.
SANTOS, W.J. Monitoramento e controle das pragas do algodoeiro. In: CIA, E.; FREIRE, E.C.; SANTOS, W.J. (Ed.). Cultura do algodoeiro. São Paulo: Potafos, 1999. p.133-180.

WEATHERSBEE III, A.A.; HARDEE, D.D. Abundance of cotton aphids (Homoptera: Aphididae) and associated biological control agents on six cotton cultivars. Journal of Economic Entomology, v.87, n.1, p.258-265, 1994.

YAMAMOTO, P.T.; PINTO, PAIVA, A.S.; GRAVENA, P.E.B. Seletividade de agrotóxicos aos inimigos naturais de pragas dos citros. Laranja, v.13, n.2, p.693708, 1992.

Recebido em 12/2/09

Aceito em 28/3/10 